\title{
Third Journal of the American Board of Family Medicine Practice-based Research Theme Issue
}

This July/August 2008 issue is our third practicebased research theme issue (the first was in January 2006 and the second in March 2007) highlighting recent studies conducted in practicebased research networks (PBRNs). Our research networks are expanding and they offer more hope for getting evidence based on real-life medicine, reflecting patients in our practices rather than carefully collected subpopulations of patients from tertiary care centers. Three studies in this issue are randomized controlled trials (RCTs): 2 from Oklahoma ${ }^{1,2}$ with positive findings, and one from Kentucky with negative results. ${ }^{3}$ One investigation used a large database from many practices ${ }^{4}$ and 5 survey studies collected key information from patients to inform our care. ${ }^{5-9}$ Two studies provide clinical information to improve practice ${ }^{10,11}$ and 2 from New Mexico examine physician behaviors. ${ }^{12,13}$ A special feature is a dialogue about Institutional Review Board training from the PBRN listserv sponsored by the Agency for Health Research and Quality. ${ }^{14}$

An excellent example of a natural history study with a comparison group is from Metronet, ${ }^{10} \mathrm{a}$ metropolitan Detroit PBRN. We finally have solid evidence that antibiotics are associated with the development of symptomatic candidal infections, which many family physicians have long suspected based on phone calls from women on days 3 or 4 of antibiotics wanting help with their vaginal infections. This article provides good evidence that our practice experience is correct.

Prevention is a key theme in many of the PBRN studies reported here. Dr. Newton ${ }^{15}$ has provided a commentary about the importance of prevention as a key feature of the new model of care. He specifically discusses the Mold et $\mathrm{al}^{1}$ project from the Oklahoma Physicians Research/Resources Network, which used a multicomponent implementation strategy consisting of feedback, benchmarking, academic detailing, facilitation, and information

Conflict of interest: The authors are editors and staff of the 7ABFM. technology support to increase the delivery of 6 preventive services in 24 practices. In a second Oklahoma Physicians Research/Resources Network study, Aspy et $\mathrm{al}^{2}$ describe a RCT with 16 practices that improved the number of women getting recommended mammograms. Again, a robust intervention including feedback with benchmarking, academic detailing, and the assistance of a practice enhancement assistant to help with practice redesign resulted in increased mammography rates.

From Pearce et $\mathrm{al}^{3}$ of the Kentucky Ambulatory Network, we learn that an RCT of an intervention many of us would expect to be useful, ie, having patients identify a support person to help with management of their chronic illness, unfortunately produced negative results. Not trying to deny the possibility that this is not a useful intervention, 2 thoughts come to mind. First, most family physicians have seen patients for whom a support person has made a large difference in their chronic illness. Second, most significant behavior change takes multiple attempts over many years. Studies of lifestyle modification often have short follow-up periods dictated by funding timeframes (this study had 9 to 12 months of follow-up) and thus may not have a long enough perspective to identify the many years of trial and error that are often required to make substantive lifestyle changes.

Sussman et $\mathrm{al}^{13}{ }^{13}$ from the Research Involving Outpatient Settings Network (RIOS Net), applied self-determination theory as an organizing structure to understand the psychology of clinicians' decisions to provide preventive counseling during the brief primary care encounter. Also from New Mexico's RIOS Net, Rhyne et a ${ }^{12}$ report a finding that PBRN membership is associated with retention of clinicians in underserved communities. Many experienced practice-based researchers will attest to the face validity of this finding; clinicians often indicate that they enjoy the camaraderie and intellectual stimulation that comes with participating in network studies. 
In collaboration with the North Carolina Family Medicine Research Network, Viera et $\mathrm{al}^{5}$ found that patients with hypertension know much about the disease, yet a significant minority still misunderstand key issues with high blood pressure, such as whether or not it can be cured. In another patient survey study, Tyler et al, ${ }^{6}$ from the Cleveland Clinic Ambulatory Research Network, explored women's use of calcium supplements. Significant predictors of calcium use were multivitamin use, self-perceived risk of osteoporosis, and older age. Leading barriers for those who never used supplements were lack of knowledge about the importance of increasing calcium intake, lack of motivation to start supplements, and the belief that dietary calcium intake alone was sufficient. Also using a patient survey methodology, Wexler et $\mathrm{al}^{8}$ from the Ohio State University Primary Care Practice-Based Research Network found that among patients with hypertension, whites were more likely than African-Americans to exercise, which may be related to their higher income level.

Compared with some countries, the US has few large, multisite databases with ongoing records for multiple patients. The military has gradually increased its ability to conduct multisite practicebased research across the country. Stephens et $\mathrm{al}^{4}$ report on efforts to identify adolescents and children at risk for hyperlipidemia through a database of $\sim 190,000$ electronic medical records in place at multiple independent military treatment facilities across the US. Furthermore, the Primary Care Education and Research Learning network researchers linked parental hyperlipidemia with their children's records. This method makes it possible to identify the child's risk immediately at the time of the encounter. In another study drawing attention to the link between parent and child risk factors, Young et al, ${ }^{7}$ from the MetroNet PBRN, highlight the important associations of parent weight and attitudes about overweight with their child's overweight status.

Bennett et al, ${ }^{11}$ representing the Interventions to Minimize Preterm and Low birth weight Infants through Continuous Improvement Techniques network, assessed the diagnostic accuracy of a 2-item prescreen for identifying possible depression during pregnancy and the postpartum period, reporting that this efficient screening device could reduce the need for further screening of a majority of women.

In perhaps the saddest news for our nation from this issue, Voorhees et al, ${ }^{9}$ from the State Networks of Colorado Ambulatory Practices and Partners, an umbrella of Colorado PBRNs, presents information about the frequency with which insured patients forego needed medical care; ie, they were underinsured in comparison with their ability to pay. Approximately one third of the patients who were insured year round did not obtain needed medical care for financial reasons. Perhaps of greatest interest is that the percentage of patients who stated their health had suffered as a result of an inability to pay was similar between patients with and without insurance. Many of us have seen these bad effects from underinsurance recurrently in practice. Most frequently, this is visible in patients unable to afford the co-pays for their medications. Zostavax has also been an acutely painful example: recently Medicare patients must be able to afford their portion to get the vaccine from Part D and many patients cannot afford the $\sim \$ 200$ for the vaccine plus any other added charges. This has resulted in significant under-immunization with this extremely helpful vaccine.

The issue of human subjects training for clinic staff who support practice-based research studies is a frequent source of confusion and consternation for PBRNs. Dolor et $\mathrm{al}^{14}$ captured a lively discussion of "The IRB Question" from members enrolled on the Agency for Health Research and Quality PBRN listserv. The thoughtful nature of the strategies to uphold research integrity in the PBRN context should be of interest to all.

\section{JABFM New Feature: Most Read/Most Cited}

We are pleased to announce our newest addition to the $7 A B F M$ website: an article statistics feature that lists the top 50 most-read and most-cited articles. For the most-read feature, article position is established by the total amount of full-text and PDF views; for the most-cited feature, article position is figured by the total number of citations that appear in HighWire-sponsored journals. Both features are updated monthly and can be accessed from our home page at www.jabfm.org. ${ }^{16}$ 
To embrace new publishing trends and technology, we look forward to providing our readership with other exciting new features in the near future. Marjorie A. Bowman, MD, MPA Anne Victoria Neale, $\mathrm{PhD}, \mathrm{MPH}$ Phillip Lupo, MLIS

\section{References}

1. Mold JW, Aspy CA, Nagykaldi Z. Implementation of evidence-based preventive services delivery processes in primary care: an Oklahoma Physicians Resource/Research Network (OKPRN) study. J Am Board Fam Med 2008;21:334-344.

2. Aspy CB, Enright M, Halstead L, Mold JW. Improving mammography screening using best practices and practice enhancement assistants: an Oklahoma Physicians Resource/Research Network (OKPRN) study. J Am Board Fam Med 2008;21:326-333.

3. Pearce KA, Love MM, Shelton BJ, et al. Cardiovascular risk education and social support (CaRESS): Report of a randomized controlled trial from the Kentucky Ambulatory Network (KAN). J Am Board Fam Med 2008;21:269-281.

4. Stephens MB, Reamy BV. A novel approach using an electronic medical record to identify children and adolescents at risk for dyslipidemia: a study from the Primary Care Education and Research Learning (PEARL) Network. J Am Board Fam Med 2008;21: 356-357.

5. Viera AJ, Cohen LW, Mitchell CM, Sloane PD. High blood pressure knowledge among primary care patients with known hypertension: a North Carolina Family Medicine Research Network (NC-FM-RN) study. J Am Board Fam Med 2008;21:300-308.

6. Tyler CV, Werner JJ, Panaite V, et al. Barriers to supplemental calcium use among women in suburban family practice: a report from the Cleveland Clinic Ambulatory Research Network (CleAR-eN). J Am Board Fam Med 2008;21:293-299.

7. Young RF, Schwartz KL, Monsur JC, West P, Neale AV. Primary care of overweight children: the importance of parent weight and attitudes about over- weight: a MetroNet study. J Am Board Fam Med 2008;21:361-363.

8. Wexler R, Feldman D, Larson D, Sinnott LT, Jones LA, Miner J. Adoption of exercise and readiness to change differ between whites and African-Americans with hypertension: a report from the Ohio State University Primary Care Practice-Based Research Network (OSU-PCPBRN). J Am Board Fam Med 2008;21:358-360.

9. Voorhees K, Fernald DH, Emsermann C, et al. Underinsurance in primary care: a report from the State Networks of Colorado Ambulatory Practices and Partners (SNOCAP). J Am Board Fam Med 2008; 21:309-316.

10. Xu J, Schwartz K, Bartoces M, Monsur J, Severson RK, Sobel JD. Effect of antibiotics on vulvovaginal candidiasis: a MetroNet study. J Am Board Fam Med 2008;21:261-268.

11. Bennett IM, Coco A, Coyne J, et al. Efficiency of a two-item pre-screen to reduce the burden of depression screening in pregnancy and postpartum: an IMPLICIT network study. J Am Board Fam Med 2008;21:317-325.

12. Sinclair-Lian N, Rhyne RL, Alexander SH, Williams RL. Practice-based research network membership is associated with retention of clinicians in underserved communities: a Research Involving Outpatient Settings Network (RIOS Net) study. J Am Board Fam Med 2008;21:353-355.

13. Sussman AL, Williams RL, Leverence R, Gloyd PW, Crabtree BF. Self determination theory and preventive care delivery: a Research Involving Outpatient Settings Network (RIOS Net) study. J Am Board Fam Med 2008;21:282-292.

14. Dolor RJ, Smith PC, Neale AV. Institutional review board training for community practices: advice from the Agency for Health Care Research and Quality practice-based research network listserv. J Am Board Fam Med 2008;21:345-352.

15. Newton WP. Improving performance in prevention. J Am Board Fam Med 2008;21:258-260.

16. American Board of Family Medicine. Journal of the American Board of Family Medicine (JABFM). Available from http://www.jabfm.org. Accessed 5 May 2008. 